\title{
Inflammatory Dermatoses of the Superficial Cutaneous Reactive Unit—Study of Morphological Features with Clinical Correlation
}

\author{
Preethi Dinesh ${ }^{1}$, Jyothi A Raj ${ }^{2}$, Yadalla Harikishan Kumar ${ }^{3}$
}

\begin{abstract}
Background and objectives: Inflammatory dermatoses of the superficial cutaneous reactive unit are a common and complex variety of clinical conditions. This study was undertaken to perform a detailed morphological evaluation of lesions classified in this category, and to correlate the clinical details to arrive at the most appropriate diagnosis.

Methodology: Skin biopsies of clinically diagnosed/suspected cases of inflammatory dermatoses were processed and stained with hematoxylin and eosin (H\&E), followed by microscopic examination.

Results: A total of 160 skin biopsies of superficial inflammatory dermatoses were studied. Lesions were categorized into papular/nonvesiculobullous (non-VB) (142 cases/88.75\%) and VB (18 cases/11.25\%) lesions. Papular lesions were frequent in males, with a peak incidence in the fourth decade. Patients presented mostly with pigmented plaques and papules over the extremities. Papular lesions were categorized based on epidermal changes: 8 cases without epidermal changes and 134 with epidermal changes. Lesions with epidermal changes were further categorized into interface dermatitis (60 cases), psoriasiform dermatitis (58 cases), and spongiotic dermatitis ( 16 cases). Commonly reported lesions were lichen planus (LP) with its variants followed by psoriasis vulgaris. VB lesions were common in the third and fourth decades, predominantly in females. These patients presented mostly with generalized vesicles. Common lesions reported were erythema multiforme (seven cases) and pemphigus vulgaris (six cases). Of the 160 cases, clinicopathological concordance was seen in 156 cases (97.5\%) and discordance in 4 cases (2.5\%).

Interpretation and conclusion: The incidence of superficial inflammatory dermatoses in our study was comparable with those reported in other studies. Despite advances in molecular techniques, morphology remains the gold standard for the diagnosis and prognosis of many inflammatory dermatoses. This study emphasizes the importance and utility of a systematic approach to superficial inflammatory dermatoses which is relevant from the treatment perspective.
\end{abstract}

Keywords: Inflammatory dermatoses, Morphology, Papules, Plaques, Vesiculobullous.

The Journal of Medical Sciences (2019): 10.5005/jp-journals-10045-00101

\section{INTRODUCTION}

The skin is the single largest organ that protects against mechanical trauma, radiation, and infection. It is concerned with thermoregulation, sensory reception, conservation, and excretion of fluid. As a sophisticated organ, it has important endocrine roles, particularly in the synthesis of vitamin $D$, powered by sun exposure. ${ }^{1}$

The first compartment of skin (epidermis, papillary dermis, and superficial vascular plexus) reacts together in many dermatological conditions and was termed the superficial cutaneous reactive unit by Clark. $^{2}$

Superficial inflammatory dermatoses are very common and comprise a wide, complex variety of clinical conditions. The immune system within the skin has limited ways in which it reacts to an antigenic stimulus and many inflammatory diseases do not show specific histological features. Accurate diagnosis can sometimes be difficult to establish, although it is essential for clinical management. A systematic approach during histological evaluation is essential to narrow the differential diagnosis, thereby achieving the most appropriate diagnosis.

The cases of superficial inflammatory dermatoses are categorized based on the approach of Elder et al., ${ }^{2}$ which was also followed by Alsaad and Ghazarian. ${ }^{3}$
${ }^{1}$ Bhagavan Mahaveer Jain Hospital, Girinagar, Bengaluru, Karnataka, India

${ }^{2,3}$ RajaRajeswari Medical College \& Hospital, Mysore Road, Bengaluru, Karnataka, India

Corresponding Author: Jyothi A Raj, RajaRajeswari Medical College \& Hospital, Mysore Road, Bengaluru, Karnataka, India, Phone: +91 9900570122, e-mail: jyoki255@yahoo.co.in

How to cite this article: Dinesh P, Raj JA, Kumar YH. Inflammatory Dermatoses of the Superficial Cutaneous Reactive Unit-Study of Morphological Features with Clinical Correlation. J Med Sci 2019;5(1):1-6.

Source of support: Nil

Conflict of interest: None

\section{Aims and Objectives}

- Morphological evaluation of skin biopsies of inflammatory dermatoses involving the superficial cutaneous reactive unit.

- To correlate the pathological features with clinical findings.

\section{Materials and Methods}

This study was undertaken over a period of 2 years. Skin biopsies of all cases clinically diagnosed as one of the variants of superficial

(c) The Author(s). 2019 Open Access This article is distributed under the terms of the Creative Commons Attribution 4.0 International License (https://creativecommons. org/licenses/by-nc/4.0/), which permits unrestricted use, distribution, and non-commercial reproduction in any medium, provided you give appropriate credit to the original author(s) and the source, provide a link to the Creative Commons license, and indicate if changes were made. The Creative Commons Public Domain Dedication waiver (http://creativecommons.org/publicdomain/zero/1.0/) applies to the data made available in this article, unless otherwise stated. 
inflammatory dermatoses, received for histopathological evaluation, were included in the study. Biopsies were processed routinely and stained with hematoxylin and eosin $(\mathrm{H} \& \mathrm{E})$, followed by microscopic examination. Relevant clinical details were correlated with histopathological findings.

\section{Inclusion and Exclusion Criteria}

All skin biopsies clinically diagnosed as one of the inflammatory dermatoses of the superficial cutaneous reactive unit were included in the study. Granulomatous diseases and vasculitides were excluded.

\section{Results}

One hundred and sixty skin biopsies clinically diagnosed or suspected to be lesions of superficial inflammatory dermatoses were included in the present study. They were categorized as papular/non-vesiculobullous (non-VB) $[n=142$ (88.75\%)] and VB $[n=18(11.25 \%)]$ lesions. Non-VB lesions were classified into those with epidermal changes and those without epidermal changes. Lesions with epidermal changes were further categorized into interface, psoriasiform, and spongiotic dermatitides.

\section{Clinical Presentation}

Of the 160 cases, 95 (59.37\%) were males and 65 (40.63\%) were females. Most cases (40) occurred in the third decade. Common presentation was in the extremities in 78 cases. Lesions were generalized in 29 cases. Most cases had overlapping clinical features: 80 patients had plaques and 79 had hyperpigmentation. Papules and scaling were seen in 49 and 40 cases, respectively.

\section{Categorization of Papular/Non-VB Lesions}

Papular/non-VB lesions were categorized into lesions without epidermal changes and lesions with epidermal changes. Lesions without epidermal changes were eight in number; these were categorized based on the type of papillary dermis and perivascular inflammation (Table 1).

The 134 papular/non-VB lesions with epidermal changes were further categorized as interface dermatitis $(n=60)$, psoriasiform dermatitis $(n=58)$, and spongiotic dermatitis $(n=16)$.

\section{Interface Dermatitis}

Vacuolar changes, lichenoid infiltrate, and both these features in combination were used as criteria to categorize this group. LP and its variants were the most common type (Tables 2 to 4). The most common clinical pattern was pigmented plaques and papules (Fig. 1).

Table 1: Categorization of papular lesions without epidermal changes $\underline{(n=8)}$

\begin{tabular}{lll}
\hline Type of inflammatory infiltrate & Histologic types & $\begin{array}{l}\text { No. of } \\
\text { cases }\end{array}$ \\
\hline Lymphocytic infiltrate & $\begin{array}{l}\text { Polymorphous light } \\
\text { eruption }\end{array}$ & 1 \\
& $\begin{array}{l}\text { Pityriasis lichenoid } \\
\text { chronica }\end{array}$ & 1 \\
Lymphoeosinophilic infiltrate & $\begin{array}{l}\text { Prurigo nodularis } \\
\text { Urticaria }\end{array}$ & 1 \\
Lymphoplasmacytic infiltrate & $\begin{array}{l}\text { Discoid lupus } \\
\text { erythematosus (DLE) }\end{array}$ & 1 \\
& Urticaria & 2 \\
Lymphohistiocytic infiltrate & Prurigo nodularis & 1 \\
\hline
\end{tabular}

Table 2: Interface dermatitis with lichenoid infiltrate $(n=23)$

\begin{tabular}{lc}
\hline Lesions & No. of cases \\
\hline LP & 9 \\
LP pigmentosus & 6 \\
Post-inflammatory hyperpigmentation & 5 \\
Hypertrophic LP & 2 \\
LP striatus & 1 \\
Total & 23 \\
\hline
\end{tabular}

Table 3: Interface dermatitis with vacuolar changes $(n=17)$

\begin{tabular}{lc}
\hline Lesions & No. of cases \\
\hline Discoid lupus erythematosus & 4 \\
Pityriasis lichenoides chronica & 4 \\
Lichen sclerosus et atrophicus & 2 \\
LP & 2 \\
LP pigmentosus & 2 \\
Hypertrophic LP & 2 \\
LP striatus & 1 \\
Total & 17 \\
\hline
\end{tabular}

Table 4: Interface dermatitis with vacuolar changes and lichenoid infiltrate $(n=20)$

\begin{tabular}{lc}
\hline Lesions & No. of cases \\
\hline LP & 14 \\
Hypertrophic LP & 3 \\
LP pigmentosus & 2 \\
Drug-induced LP & 1 \\
Total & 20 \\
\hline
\end{tabular}

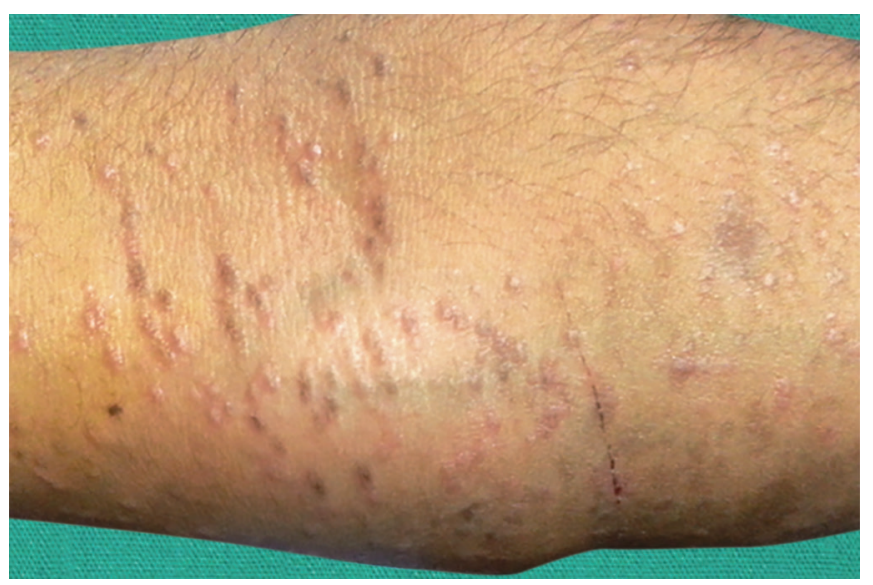

Fig. 1: LP: Small, shiny, flat-topped violaceous papules on the flexor surface of forearm

The predominant histological features in the epidermis in interface dermatitis were hyperkeratosis, acanthosis, hypergranulosis, spongiosis, and orthokeratosis. Features at the dermoepidermal junction were lichenoid infiltrate and vacuolar changes. Twenty cases had overlapping features of vacuolar changes and lichenoid infiltrate. Pigment incontinence, lymphohistiocytic infiltrate, and dilated blood vessels were seen in the dermis (Fig. 2).

\section{Psoriasiform Dermatitis (Table 5)}

Most lesions under this category were psoriasis vulgaris (25 cases). Common clinical patterns were plaques, pigmentation, and scaling. Predominant histological features observed in the 


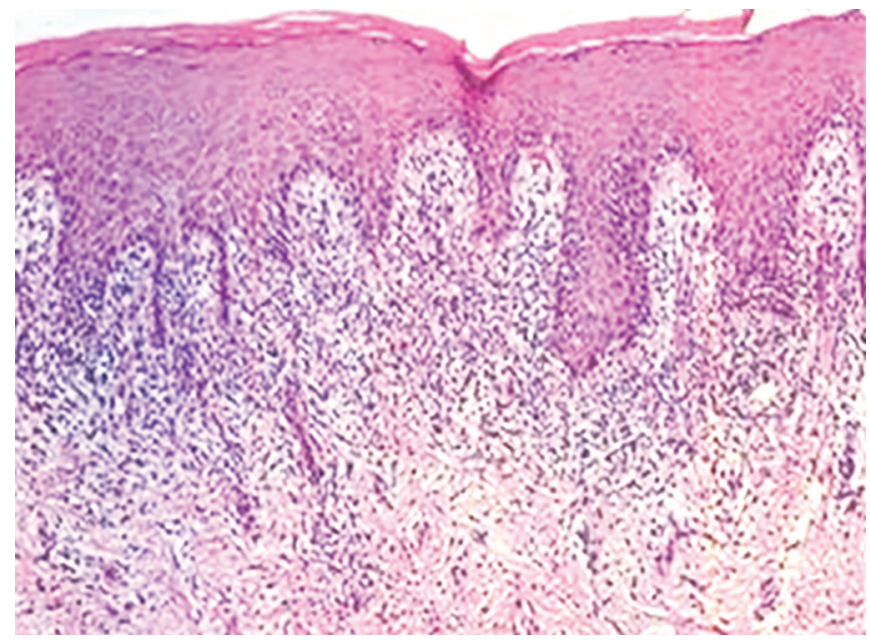

Fig. 2: LP: Photomicrograph shows hyperkeratosis, acanthosis, and basal cell degeneration in the epidermis. Dense band-like lymphohistiocytic infiltrate seen at the dermoepidermal junction (H\&E, 10X)

Table 5: Variants of psoriasiform dermatitis

\begin{tabular}{lc}
\hline Lesions & No. of cases \\
\hline Psoriasis vulgaris & 25 \\
Prurigo nodularis & 13 \\
Lichen simplex chronicus & 9 \\
Parapsoriasis & 3 \\
Seborrheic dermatitis & 3 \\
Pustular psoriasis & 2 \\
Pityriasis rubra pilaris & 2 \\
Pityriasis versicolor & 1 \\
Total & 58 \\
\hline
\end{tabular}

epidermis were hyperkeratosis in all cases, elongated rete pegs, and acanthosis. Spongiosis, keratotic plugging, and Munro's microabscesses were less common. Predominant dermal findings were perivascular inflammation and dilated/congested blood vessels. A clinicopathological correlation was seen in all cases (Figs 3 to 5).

\section{Spongiotic Dermatitis}

Under this category, seven cases of eczema, four cases of pityriasis rosea, three cases of polymorphous light eruption, and two cases of irritant contact dermatitis were reported.

Most cases presented as plaques and scales. Spongiosis, acanthosis, and hyperkeratosis were the common epidermal features. Predominant dermal findings were inflammation, vascular changes, and dermal edema (Fig. 6).

\section{VB Lesions}

Most of the VB lesions had overlapping clinical features: 11 patients had vesicles and 8 cases had erythema. Papules and bullae were seen in five and four cases, respectively (Fig. 7).

\section{Histopathological Findings of VB Lesions (Tables 6 and 7)}

All cases of pemphigus vulgaris showed split/blister at the suprabasal level and those of erythema multiforme, dermatitis herpetiformis, and bullous pemphigoid showed split at the subepidermal level. Hailey-Hailey disease showed split at the

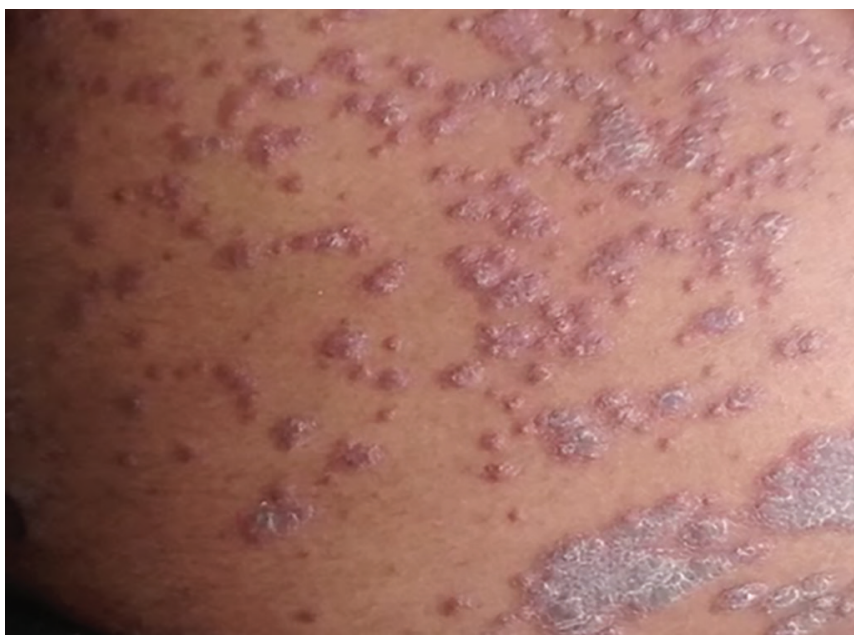

Fig. 3: Psoriasis vulgaris: Sharply demarcated, dry papules of variable sizes, covered with layers of silvery scales on the trunk

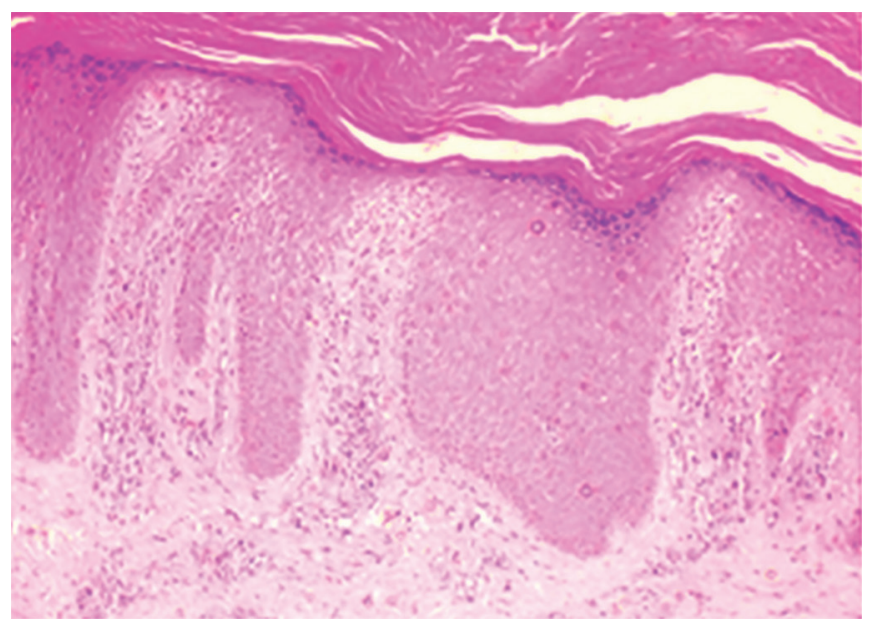

Fig. 4: Psoriasis vulgaris: Photomicrograph shows elongated rete ridges and supra papillary thinning of epidermis. Chronic inflammatory infiltrate noted in the dermis (H\&E, 10X)

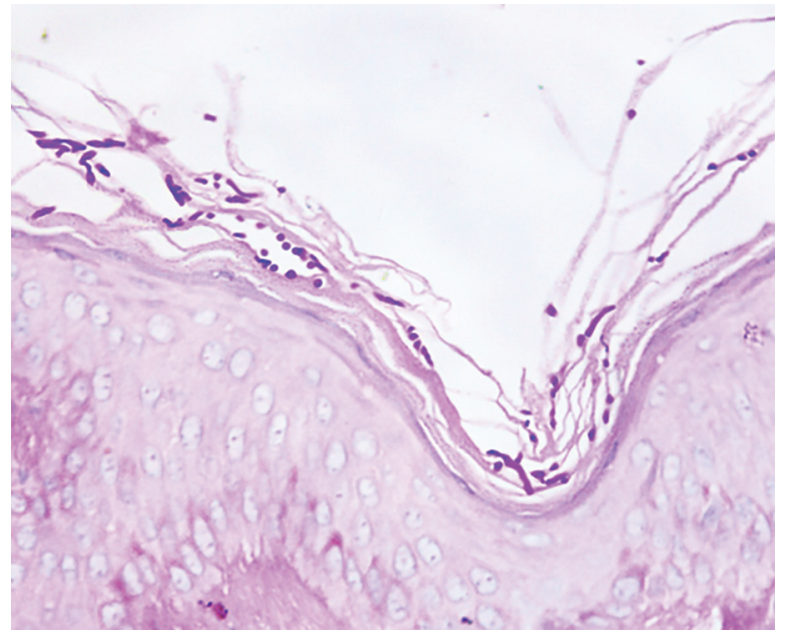

Fig. 5: Pityriasis versicolor: PAS-positive fungal hyphae in the stratum corneum (Periodic acid-Schiff (PAS), 40x) 


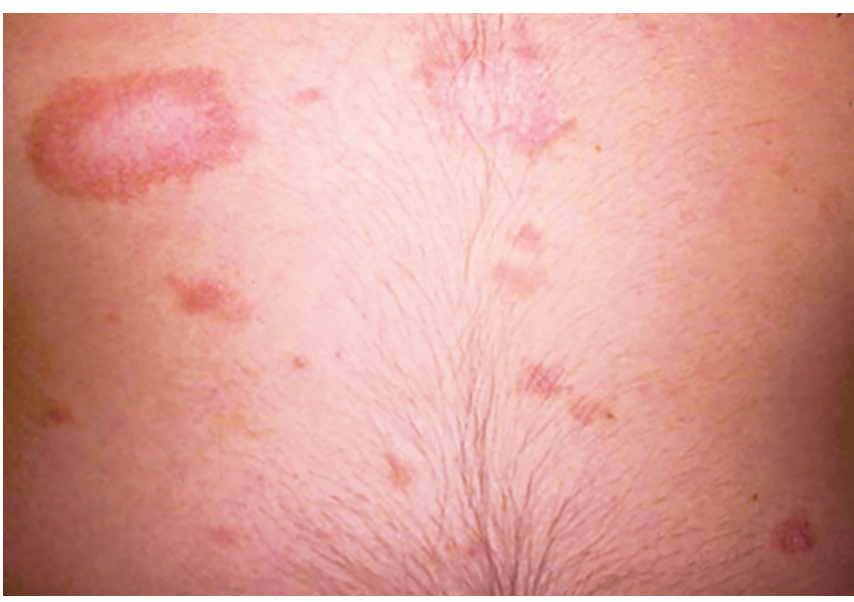

Fig. 6: Pityriasis rosea: Erythematous plaques and macules over the trunk

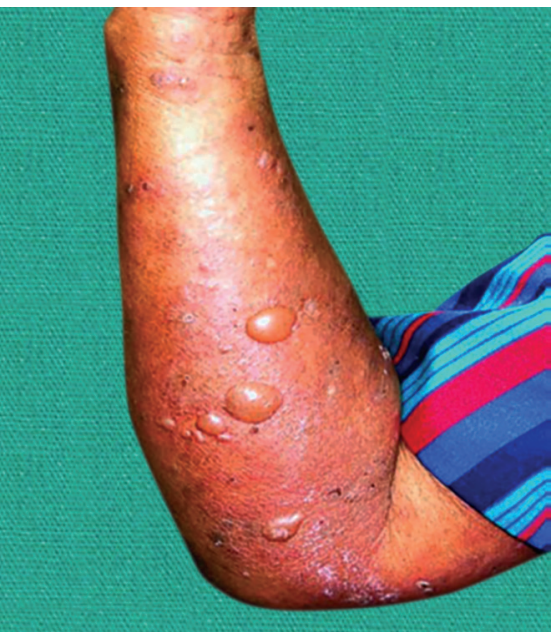

Fig. 7: Pemphigus vulgaris: Fluid-filled blisters on the forearm

Table 6: Variants of VB lesions $(n=18)$

\begin{tabular}{lc}
\hline Lesions & No. of cases \\
\hline Erythema multiforme & 7 \\
Pemphigus vulgaris & 6 \\
Dermatitis herpetiformis & 3 \\
Bullous pemphigoid & 1 \\
Hailey-Hailey disease & 1 \\
Total & 18 \\
\hline
\end{tabular}

subcorneal level. Bulla contents were acantholytic cells, eosinophils, and neutrophils in most cases (Figs 8 to 10).

\section{Clinicopathological Correlation of Lesions of Superficial Inflammatory Dermatoses}

Of the 160 cases, clinicopathological concordance was seen in 156 cases $(97.5 \%)$ and discordance in 4 cases $(2.5 \%)$.

\section{Discussion}

Pinkus was the first to describe tissue changes in the form of spongiotic, psoriasiform, and lichenoid tissue reactions. ${ }^{4}$ Interpretation of skin biopsies requires identification and integration of morphological features with their clinical diagnosis.
Table 7: VB lesions-histopathological features

\begin{tabular}{lcc}
\hline Histopathological features & No. of cases & Percentage \\
\hline Level of split & 6 & \\
Suprabasal & 10 & 33.3 \\
Subepidermal & 2 & 55.6 \\
Subcorneal & & 11.1 \\
Blister content & 9 & \\
Acantholytic cells & 7 & 50 \\
Eosinophils and neutrophils & 2 & 38.9 \\
Acellular (only fluid) & & 11.1 \\
Other features & 3 & 16.7 \\
Hyperkeratosis & 8 & 44.4 \\
Spongiosis & 5 & 27.8 \\
Basal cell degeneration & & \\
\hline
\end{tabular}

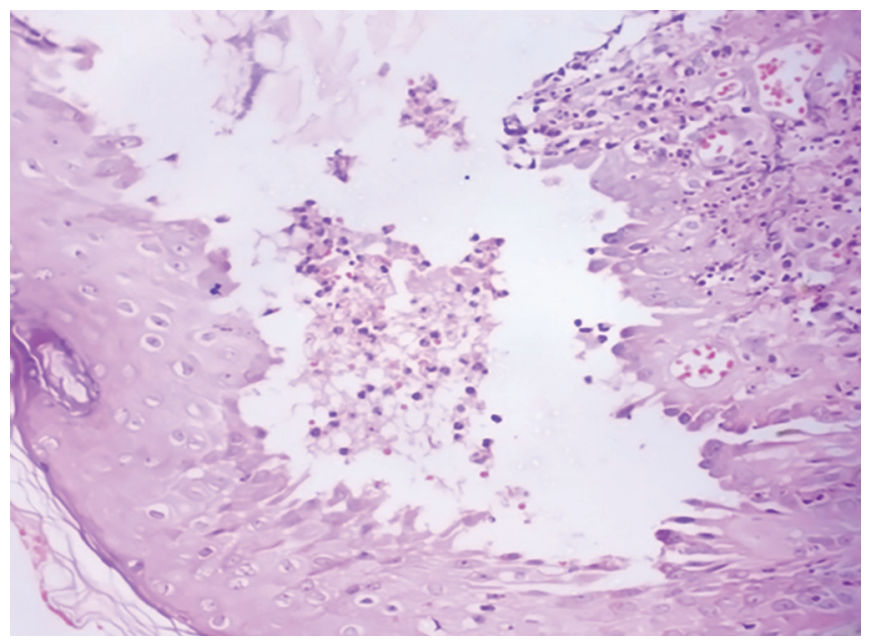

Fig. 8: Pemphigus vulgaris: Photomicrograph shows intraepidermal blister containing acantholytic cells, neutrophils, and eosinophils. Dermal papillae form villi lined by a single layer of basal keratinocytes (H\&E, 20X)

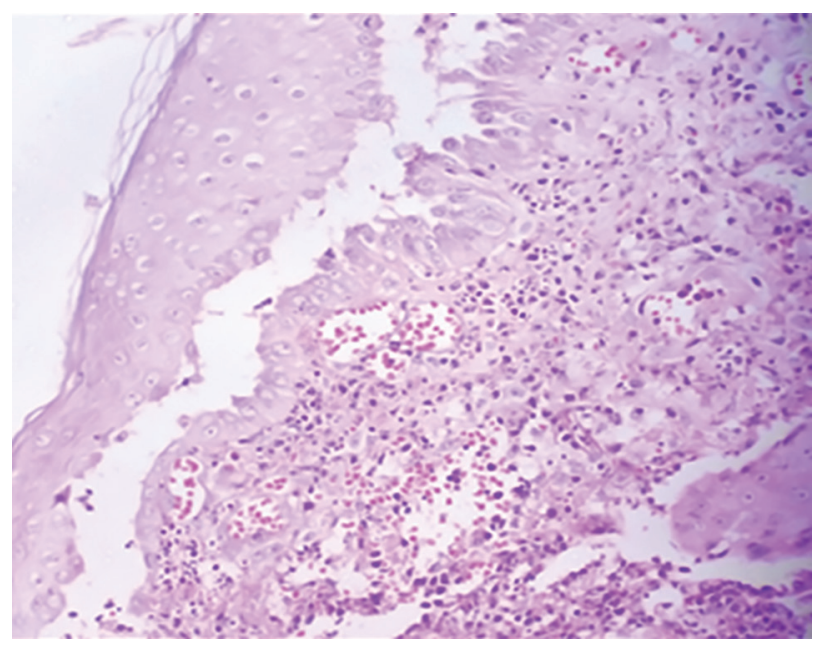

Fig. 9: Dermatitis herpetiformis: Photomicrograph shows subepidermal blister. Neutrophils, eosinophils, and acantholytic cells are seen within the blister (H\&E, 20X)

In our study, categorization of lesions is majorly based on the approach followed by Alsaad and Ghazarian. ${ }^{3}$ Of the 160 cases of 


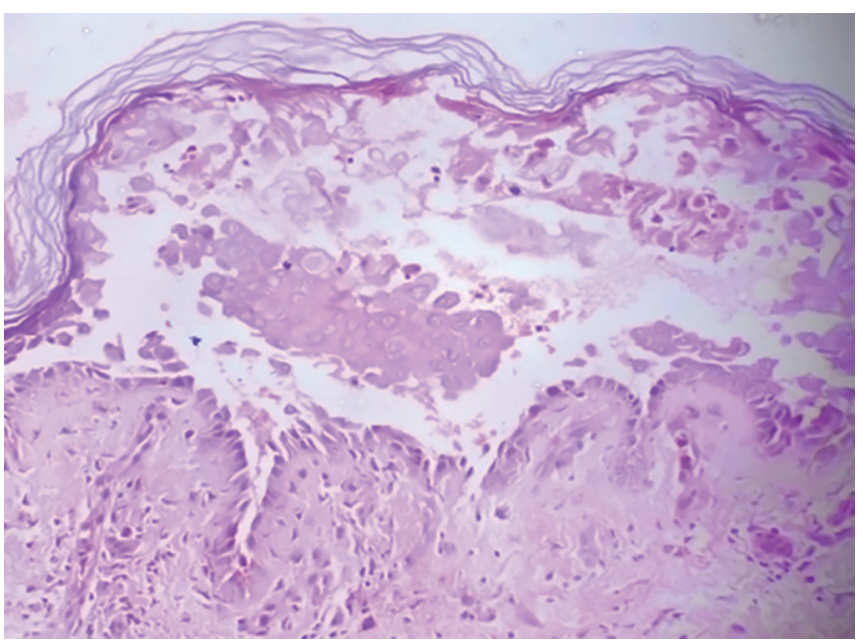

Fig. 10: Hailey-Hailey disease: Photomicrograph shows suprabasal blister containing acantholytic cells, neutrophils, and eosinophils. Basal cells protrude into the blister (H\&E, 20X)

superficial inflammatory dermatoses, 142 were papular/non-VB lesions and 18 were VB lesions.

\section{Papular/Non-VB Lesions}

These lesions were categorized based on the presence/absence of epidermal changes. Eight lesions were without epidermal changes and 134 were with epidermal changes. Among the lesions without epidermal changes, lymphocytic infiltrate in the papillary dermis was common in all histological types, similar to the observations by Alsaad and Ghazarian ${ }^{3}$ in their cases. Lesions with epidermal changes were categorized into interface dermatitis (60 cases), psoriasiform dermatitis (58 cases), and spongiotic dermatitis (16 cases).

Chaudhary et al. ${ }^{5}$ and D'Costa et al. ${ }^{6}$ reported a similar incidence of interface dermatitis to our study. The predominant histological features of hyperkeratosis, acanthosis, lichenoid infiltrate, and pigment incontinence were reported in this study, corroborated with the observations made by Hegde et al. ${ }^{7}$ In psoriasiform dermatitis, most histological features in the epidermis were similar to the findings reported by Raghuveer et al. ${ }^{8}$ Munro's microabscesses are not found in early lesions of psoriasis and were reported only in $6.9 \%$ cases in the present study. Raghuveer et al. noted microabscesses in $20.5 \%$ cases. Dominant histopathological findings in spongiotic dermatitis were spongiosis, acanthosis, and hyperkeratosis. Dermal inflammation showed predominance of lymphoeosinophilic infiltrate followed by lymphohistiocytic infiltrates in our study and these observations were comparable with the findings of Younas et al. ${ }^{9}$ Prasad et al. ${ }^{10}$ reported more number of cases with lymphohistiocytic infiltrates.

\section{Clinicopathological Correlation of Papular/Non-VB Lesions (Table 8)}

In our study, clinicopathological concordance of papular/non-VB lesions was better than other studies. Of the 60 cases of interface dermatitis in the present study, 57 cases (95\%) were concordant with clinical diagnosis. Hegde et al. ${ }^{7}$ reported $87.2 \%$ concordance in their study of 125 cases of interface dermatitis. Psoriasiform dermatitis showed the clinicopathological correlation in all the cases (100\%) in the present study. This was comparable with the study done
Table 8: Clinicopathological correlation of papular/non-VB lesions

\begin{tabular}{lccc}
\hline $\begin{array}{l}\text { Clinicopathological } \\
\text { correlation }\end{array}$ & $\begin{array}{l}D^{\prime} \text { Costa } \\
\text { et al. }{ }^{6}(\%)\end{array}$ & $\begin{array}{l}\text { Kaler } \\
\text { et al. }{ }^{11}(\%)\end{array}$ & $\begin{array}{l}\text { Present } \\
\text { study (\%) }\end{array}$ \\
\hline Concordance & $149(92.5)$ & $137(90.6)$ & $138(97.2)$ \\
Discordance & $12(7.5)$ & $14(9.3)$ & $4(2.8)$ \\
Total & $161(100)$ & $151(100)$ & $142(100)$ \\
\hline
\end{tabular}

by D'Costa et al. ${ }^{6}$ Spongiotic dermatitis showed a concordance of $93.75 \%$ (15 of 16 cases) in the present study. Kaler et al. ${ }^{11}$ in a study of 25 cases of spongiotic dermatitis observed $92.3 \%$ clinical correlation.

There is considerable overlap of lesions among psoriasiform, spongiotic, and lichenoid dermatitis. Drug reactions and discoid lupus erythematosus have psoriasiform features with interface changes. ${ }^{11}$ Eczematous dermatitis and psoriasis may have significant clinical overlap. Eczema has more spongiosis, less uniform hyperplasia, and a retained or thickened granular layer which are the differentiating features from psoriasis. ${ }^{12}$ In partially treated psoriasis cases, the granular layer may be present which is a feature of spongiotic dermatitis; hence, clinical details are important for accurate diagnosis. ${ }^{3,11}$

Categorization of papular/non-VB lesions into three distinct entities is a useful approach in reaching the diagnosis. This categorization is also relevant from the treatment perspective. Systemic steroids are to be avoided in psoriasiform lesions, while it can be used as a mode of treatment in lichenoid lesions. Similarly, cyclosporine or azathioprine is used as a last resort in severe cases of spongiotic dermatitis, while it can be used as a first line of treatment in psoriasiform and lichenoid lesions. ${ }^{13}$ Hence, appropriate placement of the lesions in each category will aid in differentiating the lesions sooner and help in management. ${ }^{3,11}$

\section{VB Lesions}

VB skin diseases represent a group of dermatoses with protean manifestations, having varied etiopathogenesis, but common clinical presentation of vesicles, pustules, or bullae. Among them, the pemphigus group is the commonest. ${ }^{14,15}$ Histopathological diagnoses are based on the level of blister separation, inflammatory infiltrate, and altered keratinocytes, such as acanthocytes. ${ }^{14,16}$ In the present study, the distribution of VB lesions was generalized. Most cases presented as vesicles. These patterns were comparable with the study done by Arundhathi et al. ${ }^{14}$ Subepidermal blister was the predominant feature in our study. Blister contents of inflammatory cells were reported in about half the cases, comparable to the study done by Deepti et al. ${ }^{17}$

\section{Clinicopathological Correlation of VB Lesions}

All the 18 cases were concordant with clinical diagnoses (100\%) in our study. Krishnamurthy et al. ${ }^{15}$ reported $64.8 \%$ concordance, while Arundhathi et al. ${ }^{14}$ reported $72.2 \%$ concordance with clinical diagnosis.

\section{Conclusion}

Inflammatory dermatoses of the superficial cutaneous reactive unit are very common and comprise a wide, complex variety of clinical conditions. Morphology remains the gold standard for their diagnosis. In view of their complexity, knowledge of clinical details, detailed microscopic evaluation to recognize their myriad histological patterns, and a schematic approach for categorization 
and diagnosis, all contribute to arriving at the most appropriate diagnosis and patient management.

\section{References}

1. Lazar AJF, Murphy GF. The Skin. Chapter 25. In: Kumar V, Abbas AK, Fausto N, Astor JC, ed. Robbins and Cotran Pathologic Basis of Disease. 8th ed. New Delhi: Saunders Elsevier, 2011; pp.1166-1204.

2. Elder DE, Elenitsas R, et al. Outline of cutaneous pathology. Chapter 5. In: David E. Elder, ed. Lever's Histopathology of the Skin, 10th ed. New Delhi: Wolters Kluwer/Lippincott Williams and Wilkins, 2009; pp.83-114.

3. Alsaad KO, Ghazarian D. My Approach to Superficial Inflammatory Dermatoses. J Clin Pathol 2005;58:1233-1241. DOI: 10.1136/ jcp.2005.027151.

4. Mehregan AH. Evolution of a Dermatopathologist-A 35-year Experience. The Gulf Journal of Dermatology 1994;1:2:1-10.

5. Chaudhary RG, Chauhan AP, et al. Study of clinic-histopathological correlation of papulosquamous disorders at tertiary care hospital. Sch J App Med Sci 2015;3:1154-1158.

6. D'Costa, Bharambe BM. Spectrum of non-infectious erythematous, papular and squamous lesions of the skin. Indian J Dermatol 2010;55:225-228. DOI: 10.4103/0019-5154.70666.

7. Hedge VK, Khadilkar UN. A clinicopathological study of interface dermatitis. Indian J Pathol Bacteriol 2014;57:386-389.

8. Raghuveer C, Shivanand DR, et al. A clinico-histopathological study of psoriasis. Int J Sci Stud 2015;3:176-179.
9. Younas $M$, Haque A. Spectrum of Histopathological Features in Non Infectious Erythematous and Papulosquamous Diseases. Int J Pathol 2004;2:24-30.

10. Prasad D, Mittal RR, et al. Pityriasis rosea - a histopathological study. Indian J Dermatol Venereol 2000;66:244-246.

11. Kaler AK, Parthiban R. An approach to the diagnosis of superficial inflammatory dermatosis. Hum Physiol 2013;62:17617-17622.

12. Billings SD, Cotton J. Spongiotic dermatitis. Chapter 2. In: Inflammatory dermatopathology: A pathologist's survival guide. 9th ed. New York: Springer Science + Business media LLC, 2011; pp.5-19.

13. Griffiths CEM, Barker JNWN. Psoriasis. Chapter 20. In: Burns T, Breathnach S, Cox N ed. Rooks Text Book of Dermatology, 8th ed. West Sussex, UK: John Wiley and Sons Ltd, 2010; pp.845-980, vol. 1.

14. Arundhathi S, Ragunatha S, et al. A Cross-sectional Study of Clinical, Histopathological and Direct Immunofluorescence Spectrum of Vesiculobullous Disorders. J Clin Diagn Res 2013;7:2788-2792. DOI: 10.7860/JCDR/2013/7019.3760.

15. Krishnamurthy $T$, Shivarudrappa AS, et al. Histopathological study of vesiculobullous lesions of skin. Int J Adv Biol Biomed Res 2015;6: 4966-4972. DOI: 10.5455/ijmsph.2014.050420141.

16. Hong WU, Allan AE, et al. Non-infectious Vesicobullous and Vesicopustular Diseases. Chapter 9. In: David E Elder, ed. Lever's histopathology of the skin. 10th ed. New Delhi: Wolters Kluwer/ Lippincott Williams and Wilkins, 2009; pp.581-674.

17. Deepti SP, Sulakshana MS, et al. A histomorphological study of bullous lesions of skin with special reference to immunofluorescence. Int J Curr Res Acad Rev 2015;3:29-51. 